\title{
Smart antenna with automatic beam switching for mobile communication
}

\author{
Yuchen Ma®l, Junhong Wang ${ }^{*}$, Yujian Li, Meie Chen, Zheng Li and Zhan Zhang
}

\author{
* Correspondence: wangjunh@bjtu. \\ edu.cn \\ Key Laboratory of All Optical \\ Network and Advanced \\ Telecommunication Network of \\ MOE, Beijing Jiaotong University, \\ Beijing 100044, China
}

\begin{abstract}
A new kind of smart antenna capable of automatically switching its main beam to track a moving target is presented. The antenna, which is suitable for mobile communication in long straight spaces, such as railways or highways, integrates a sensing element, signal processing element, and radiating element. The sensing element works based on a frequency-modulated continuous wave and delivers a beat frequency signal containing environmental information to the signal processing element, which is used to control the excitation of the radiating element. To verify the efficiency of the proposed antenna, a prototype is fabricated and implemented in a real corridor scenario. Furthermore, the error vector magnitude (EVM) along the test path is investigated to evaluate the system performance when using the proposed antenna. The results show that this kind of smart antenna is capable of improving mobile communication quality and decreasing energy consumption. Therefore, it is a promising candidate for mobile communication.
\end{abstract}

Keywords: Smart antenna, Automatic beam switching, Mobile communication, Lowenergy consumption, Moving target tracking

\section{Introduction}

With the development of electronic technology and the advent of mobile communication, the construction of flexible and variable short-range wireless communication channels for environmental adaptability has become an important task in the design of mobile communication systems, in which antennas play a key role. For such systems, low-cost antennas may not always be emphasized, but more likely, in the case of moderate cost, antennas have flexible and intelligent characteristics and are combined with artificial intelligence to achieve environmentally cognitive intelligence. Such smart antennas can reduce the energy consumption and increase the reliability of wireless communications.

The concept of smart antennas has existed for many years and has received wide attention [1]. Many kinds of antennas have found potential applications in smart communication and detection systems. In [2], an antenna with the capability of radiation pattern changing between six states in the azimuth plane, which is controlled by $\mathrm{p}-\mathrm{i}-\mathrm{n}$ diodes, is proposed. In [3], a compact electronically steerable passive array with six folded monopoles that can realize frequency-controlled scanning by using varactors is

(c) The Author(s). 2020 Open Access This article is licensed under a Creative Commons Attribution 4.0 International License, which permits use, sharing, adaptation, distribution and reproduction in any medium or format, as long as you give appropriate credit to the original author(s) and the source, provide a link to the Creative Commons licence, and indicate if changes were made. The images or other third party material in this article are included in the article's Creative Commons licence, unless indicated otherwise in a credit line to the material. If material is not included in the article's Creative Commons licence and your intended use is not permitted by statutory regulation or exceeds the permitted use, you will need to obtain permission directly from the copyright holder. To view a copy of this licence, visit http://creativecommons.org/licenses/by/4.0/. 
proposed. In [4], a smart antenna with beam switching capability that can realize beam switching between $0,90,180$, and $270^{\circ}$ by means of diodes is presented.

In [5], a smart antenna with beam and polarization switching capabilities in the azimuth plane is proposed. In [6], a two-dimensional scanning smart antenna for cognitive radio is proposed. In [7], a graphene antenna with dynamic control of the radiation pattern by means of setting specific chemical potentials based on graphene is presented. In [8], a smart antenna array with different types and nonuniform distributed elements that can process multiple signals at multiple frequencies simultaneously is proposed. In [9], a shape changeable parabolic smart antenna is designed to transmit a signal with a given gain to desired positions by controlling the shape of the antenna using a shapememory alloy. In [10], a smart antenna system with interference mitigation capability that is realized by generating radiation nulls in the interferer direction is presented. In [11], a novel reconfigurable adaptive linear array is proposed for finding the optimal radiation direction in which the spatial correlation coefficient is minimal, and in [12], the antenna is further formed to minimize the spatial correlation coefficient. In [13], a neural network-based smart antenna is proposed for multiple source tracking. In [14], a beam-steering reconfigurable antenna for automatically searching for the maximum receiving signal power is proposed. In [15], a beam tracking scheme in the downlink of $5 \mathrm{G}$ cellular radio access that can choose candidate beams based on mobility-reference signals is proposed. However, although these antennas have potential applications in smart mobile communication systems, external control systems must be used, and the antennas themselves do not have the function of automatic sensing and adjusting their characteristics according to environmental information. Therefore, these antennas cannot be seen as the real "smart" antennas.

The smart antenna proposed in this paper itself has a target distance sensing function, the capability to process sensed target data, and the ability to automatically make judgments and switch its beams. All these functions of sensing, data processing and automatic switching are integrated into a single smart antenna. Although the antenna is not as small as fractal antennas [16] [17], it can be easily placed on a ceiling. It works similarly to the human eye and always keeps the target in an optimum radio link state. The method and experiment are introduced in Section II. The design scheme and prototype of the antenna are presented in Section III, and the performance of the antenna is verified by measurement in Section IV. Finally, conclusions are drawn in Section V.

\section{Method and experiment}

First, the constitution of the smart antenna is given. The principle and structure of each element are presented, and the integration of all elements is demonstrated. The experiment is based on numerical simulations and measurements. The radiating element is simulated and measured. In addition, to verify the effectiveness of the proposed antenna, the properties of the smart antenna are tested in a real corridor. The analysis shows that the proposed antenna is useful and effective for mobile communication.

\subsection{Antenna description}

A human-eye-like antenna has the capability of perceiving environmental changes and making corresponding adjustments during operation. Similar to the human eye, when 
the antenna detects a variation in distance from a target, the radiation pattern of the antenna will immediately change to track the target and keep the target in the focus region of the antenna. Theoretically, the radiation pattern of the antenna must be changed continuously by the beam scanning technique. However, for simplicity, the radiation pattern is changed only by switching excitation between three different radiating sub-elements in this paper.

\subsection{Antenna configuration}

The antenna proposed in this paper consists of three integrated parts, that is, the sensing element, signal processing element, and radiating element, as shown in Fig. 1. The sensing element can be acoustic, electronic or any other kind of environment sensor: in this paper, two $24 \mathrm{GHz}$ frequency-modulated continuous wave (FMCW) distance sensors are used. The signal processing element extracts distance information of targets from the output signal of the sensors, and in this paper, Texas Instruments model TMS320F28335 are used. The radiating element transmits and receives the RF signal to and from the desired directions: two Yagi-Uda antennas and one patch antenna are integrated to construct the radiating element. When the proposed antenna is in operation, excitation can be automatically switched between the three radiating subelements in accordance with the presupposed trigger positions of vehicles. The mobile communication system only sends an RF signal to the antenna as usual; the antenna itself automatically establishes and changes the wireless communication channel in real time and keeps the channel in the optimum state.

\subsection{Sensing element}

In the sensing element, two CFK024-5A FMCW distance sensors are used [18]; the sensors work at $24 \mathrm{GHz}$ with dimensions of $25 \mathrm{~mm} \cdot 25 \mathrm{~mm} \cdot 6 \mathrm{~mm}$. The sensing element is powered by a $5 \mathrm{~V} \mathrm{DC}$ source and is stimulated by a triangle wave. The outputs of the sensors are beat frequency signals obtained by mixing the transmitting and receiving signals, from which distance information of the targets can be obtained [18].

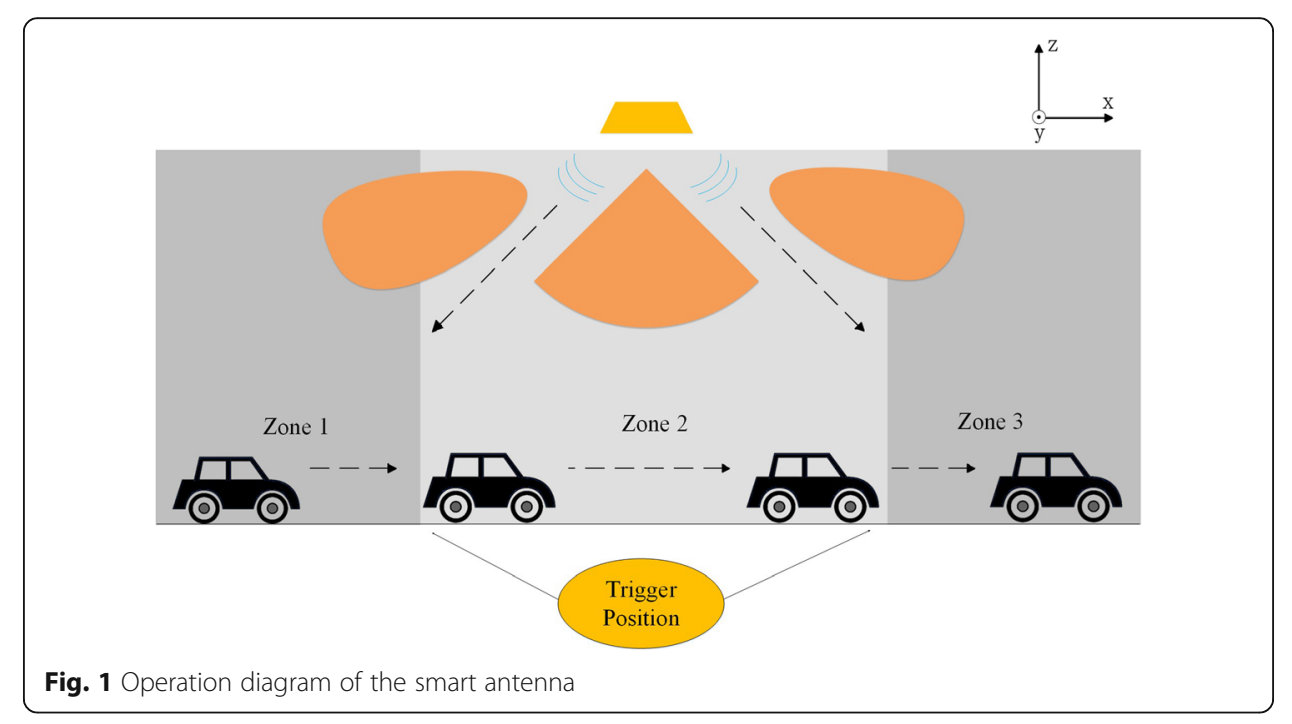


The radiators on the sensors have beamwidths of 80 and $32^{\circ}$ in the horizontal and vertical planes, respectively, and the output RF power can reach $15 \mathrm{dBm}$. The sensors work based on frequency-modulated waves, and the sensing distance $R$ is given by [19]:

$$
R=f d c T / 2 B
$$

where $f_{d}$ is the frequency of the beat frequency signal, $B$ and $T$ are the sweep bandwidth and duration, respectively, and $c$ denotes the velocity of light. Notably, $B$ is determined by a voltage-controlled oscillator ( $\mathrm{VCO}$ ), which is excited by a triangle wave with a repeat frequency of $80 \mathrm{~Hz}$, as illustrated in Fig. 2. The amplitude variation range of the triangular wave is set from 0.1 to $1.8 \mathrm{~V}$, corresponding to a sweep bandwidth of $150 \mathrm{MHz}(23.25-24.75 \mathrm{GHz})$. Figure 2 also shows the amplified output signal of the sensors, which contains the beat frequency signal, as shown by the ripple wave superimposed on the triangle wave. Notably, the frequency of the sweep wave is linearly correlated with the instantaneous amplitude of the frequency-modulated wave (triangle wave). For example, when the value of the modulation signal is $0.1 \mathrm{~V}$, the frequency of the sweep wave is $23.25 \mathrm{GHz}$. When the modulation signal increases, the frequency of the sweep wave also increases and reaches its peak at $24.75 \mathrm{GHz}$ (corresponding to 1.8 $\mathrm{V})$. Hence, the beat frequency signal is extracted from the transmitting and receiving signals (reflected from the targets) by a mixer during every scanning period, as illustrated in Fig. 3. Therefore, future work will focus on how to obtain $f_{d}$. Additionally, the Doppler effect should be considered when a vehicle is traveling at high speed. For the proposed antenna, the Doppler effect is similar to that of the commonly used basestation antenna with relatively high gain. When seen from different elements of the proposed antenna, the Doppler effect of the two Yagi elements is larger than that of the patch antenna.

\subsection{Signal processing element}

As mentioned above, the beat frequency signal is a time-domain waveform. Therefore, a signal processing circuit should be designed to process the analog signal before analog-to-digital conversion (ADC), which includes a two-stage preamplifier, an active fourth-order high-pass filter, a single-stage amplifier and a booster circuit (the ADC

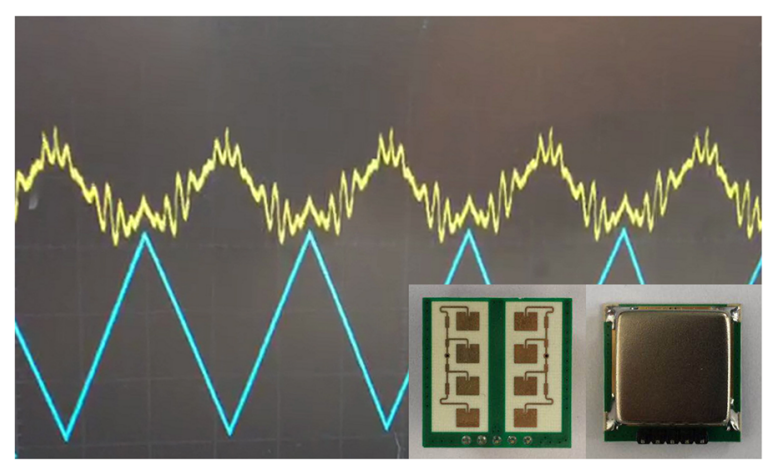

Fig. 2 Modulation signal (blue line) and amplified output signal (yellow line) from the FMCW distance sensor, whose prototype is shown in the bottom-right corner. The photo was obtained from an oscilloscope 


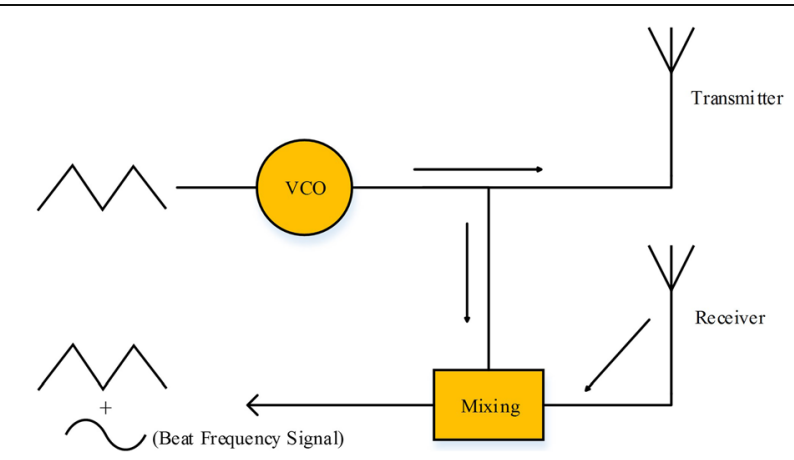

Fig. 3 Block diagram of the FMCW distance sensor

can only receive signals greater than 0), as shown in Fig. 4. Note that the beat frequency signal determined by the target distance ranges from approximately $500 \mathrm{~Hz}$ to approximately $3 \mathrm{kHz}$ in this paper, which is superimposed on the frequency-modulated wave $(80 \mathrm{~Hz})$ as the output signal of the sensors shown in Fig. 3. To obtain the beat frequency signal, we removed the triangle wave using an active fourth-order high-pass filter with a stop band less than $500 \mathrm{~Hz}$. By means of ADC, with a sampling rate of $781.25 \mathrm{KHz}$ integrated on a DSP of type TMS320F28335, we obtain the digital beat frequency signal. To further obtain the frequency of the digital beat frequency signal and the corresponding distances of targets, DFT is considered. To reduce the consumption of computational resources and time, methods with low computational cost, such as FFT or the modified fractional derivative of the Riemann $\zeta$ function, should be used [20]. Here, a 128-point FFT unit is adopted, which is expressed by

$$
X(k)=\sum_{n=0}^{\frac{N}{2}-1} x_{1}(n) W_{N / 2}^{k n}+W_{N}^{k} \sum_{n=0}^{\frac{N}{2}-1} x_{2}(n) W_{N / 2}^{k n}
$$

where $x(n)=x_{1}(n)+x_{2}(n), N=128$, and $x_{1}(\mathrm{n})$ and $x_{2}(\mathrm{n})$ are even and odd sequences, respectively. In this way, the numbers of calculations can be reduced to $(N / 2) \log _{2} N$ for multiplication and $\operatorname{Nog}_{2} N$ for addition.

\subsection{Radiating element}

The radiating element consists of two Yagi-Uda antennas [21] for endfire coverage and one patch antenna [22] for broadside coverage, as shown in Fig. 5. The antennas are designed on a Rogers 6010 substrate with $\varepsilon_{r}=10.2$ and $\tan \delta=0.0023 \varepsilon \mathrm{r}=10.2 \tan \delta=$ 0.0023 and share the same ground plane with sizes of $161.14 \mathrm{~mm} \times 119.00 \mathrm{~mm} \times 0.635$ $\mathrm{mm} ; \mathrm{mm} \times 119.00 \mathrm{~mm} \times 0.635 \mathrm{~mm}$. The distance between the antennas is set to $42.05 \mathrm{~mm}$ to reduce coupling. The two Yagi-Uda antennas are located at two opposite edges of the substrate, while the patch antenna is located at the middle of the substrate. With this design, the radiation beams of the antennas can cover zones of 1,2 , and 3 simultaneously or separately by exciting the corresponding antennas, as shown in Fig. 1. The parameters of the antennas are given in Table 1 , and the radiating element is simulated using CST. Fig. 6 shows the fabricated radiating element. 


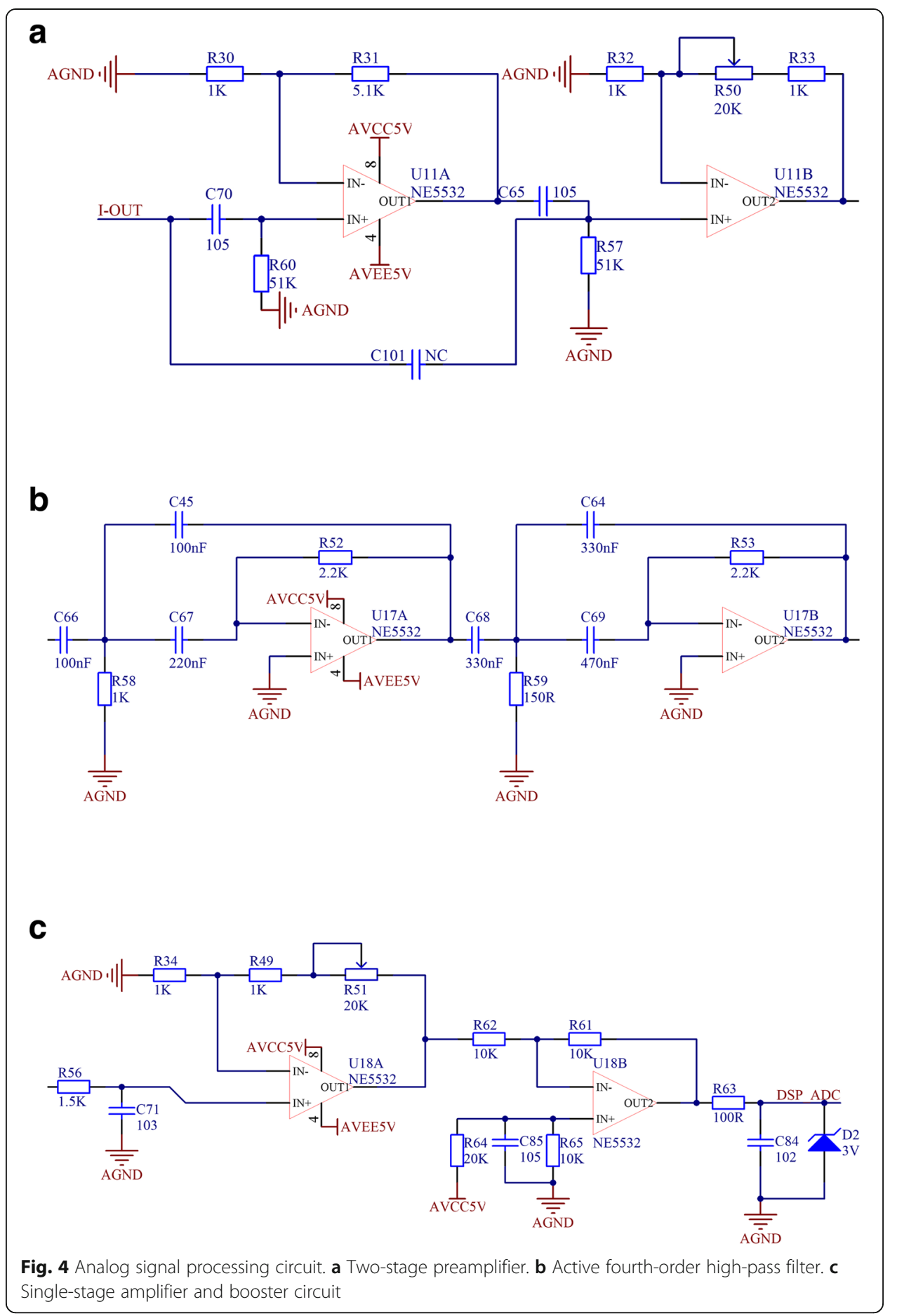

\subsection{Setup of the smart antenna}

As illustrated in Fig. 7, the sensing element, signal processing element, and radiating element are integrated to construct the smart antenna. An FR4 printed circuit board (PCB) with an overall size of $110.00 \mathrm{~mm} \times 85.00 \mathrm{~mm} \times 1.75 \mathrm{mmnmm} \times 85.00 \mathrm{~mm} \times 1.75 \mathrm{~m}$, which contains a signal processing circuit and DSP, is fixed on the back of the ground plane of the antenna, sandwiching a foam layer with a thickness of $8 \mathrm{~mm}$. The diffraction effect to the PCB from radiating elements can be overlooked [23, 24]. The circuit is powered by a 


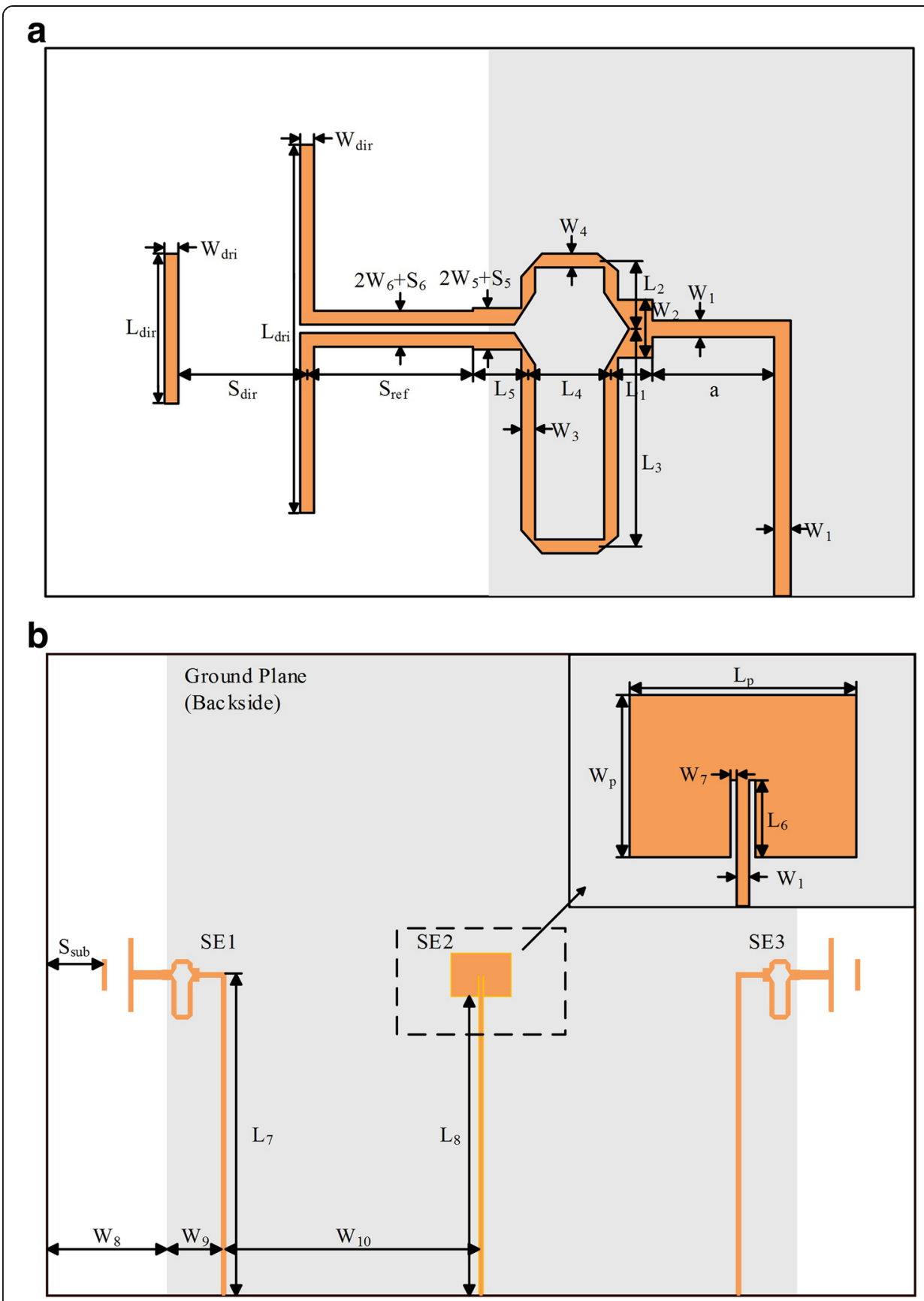

Fig. 5 Structure of the radiating element. a Details of the Yagi-Uda antennas. b Schematic of the radiating element with details of the patch antenna, SE1-SE3 denote radiating sub-elements

$12 \mathrm{~V} \mathrm{DC}$ source. The ground plane of the antenna has a size of $119.00 \mathrm{~mm} \times 117.20$ mmwmm, and it plays a role in screening the interference from the circuit behind. The two FMCW distance sensors powered by the PCB are installed on the substrate edge of the antenna at opposite edges and are placed as far as possible away from the antenna input terminal to reduce their influence. In addition, the sensors are installed on two small rotatable holders. Once the trigger positions and the distances between the antenna and targets are given, we can rotate the sensors to the appropriate positions to improve the 
Table 1 Parameters of the proposed radiating element

\begin{tabular}{llllll}
\hline Parameter & $\begin{array}{l}\text { Value } \\
(\mathbf{m m})\end{array}$ & Parameter & $\begin{array}{l}\text { Value } \\
(\mathbf{m m})\end{array}$ & Parameter & $\begin{array}{l}\text { Value } \\
(\mathbf{m m})\end{array}$ \\
\hline$W_{1}$ & 0.6 & $W_{p}$ & 7.8 & $L_{8}$ & 55.6 \\
$W_{2}$ & 2.1 & $W_{\text {dir }}$ & 0.5 & $L_{p}$ & 10.9 \\
$W_{3}$ & 0.5 & $W_{\text {dri }}$ & 0.5 & $L_{\text {dir }}$ & 5.41 \\
$W_{4}$ & 0.5 & $L_{1}$ & 1.5 & $L_{\text {dri }}$ & 13.3 \\
$W_{5}$ & 0.6 & $L_{2}$ & 2.46 & $S_{5}$ & 0.5 \\
$W_{6}$ & 0.5 & $L_{3}$ & 7.86 & $S_{6}$ & 0.3 \\
$W_{7}$ & 0.3 & $L_{4}$ & 3 & $S_{\text {ref }}$ & 6 \\
$W_{8}$ & 21.97 & $L_{5}$ & 2 & $S_{\text {dir }}$ & 4.91 \\
$W_{9}$ & 10.3 & $L_{6}$ & 3.7 & $S_{\text {sub }}$ & 10.41 \\
$W_{10}$ & 47.2 & $L_{7}$ & 59.8 & $a$ & 4.4 \\
\hline
\end{tabular}

detection accuracy. The proposed smart antenna is sufficiently lightweight to be readily mounted on the ceiling, as shown in Fig. 8.

Notably, although the proposed antenna is capable of tracking multiple targets simultaneously by exciting all or several radiating elements, for simplicity, this paper focuses on the case where only one target is tracked, and only one antenna is excited at a time to illustrate the efficiency of the smart antenna.

The operation principle of the proposed antenna is shown in Fig. 9. The procedure of beam switching between different regions is illustrated in Fig. 5 and Fig. 7. When the antenna is in operation, the sensors are active, and when sensor 1 receives a signal from a vehicle, for example, the left Yagi-Uda antenna (sub-element 1) radiates a wave to zone 1. When the vehicle moves to the presupposed position (closer to the antenna), the signal processing element generates a signal and sends it to the switch to automatically realize an excitation handover between the left Yagi-Uda antenna and the middle patch antenna, and the radiation area is changed from zone 1 to zone 2. Here, switches with RS14SN12T18 SP4T are used to control the on-off status of the input ports of the three radiating sub-elements. Identically, when the vehicle moves towards the right direction and is far from the smart antenna, the right Yagi-Uda antenna (radiating sub-element 3) is excited, and zone 3 will become the illuminating area as soon as the vehicle reaches the second trigger position. The antenna in this paper is proposed mainly for applications in long straight spaces, such as subways or corridors. The two beams of the Yagi-Uda antennas with higher gain point to the two ends of the long straight space and cover the regions far from the smart antenna, as denoted by zones 1 and 3 in Fig. 1, while the beam from the patch antenna covers the region near the antenna, as denoted by zone 2 in Fig. 1.

\section{Results and discussion}

Measurement systems, including measurements in a microwave chamber and in a realistic scenario, were established to verify the efficiency of the proposed smart antenna.

\subsection{Radiation characteristics}

The S-parameters of the proposed antenna were measured first by an Agilent E8363C PNA network analyzer, and the results are shown in Fig. 10. Note that sub-elements 1, 


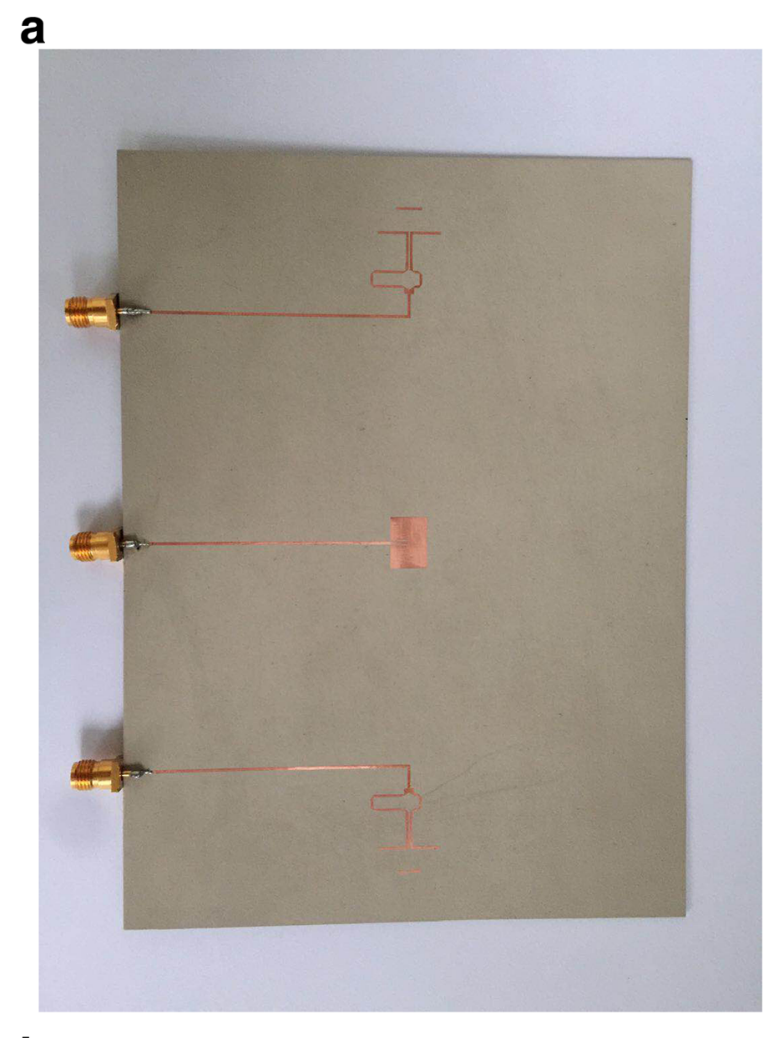

b

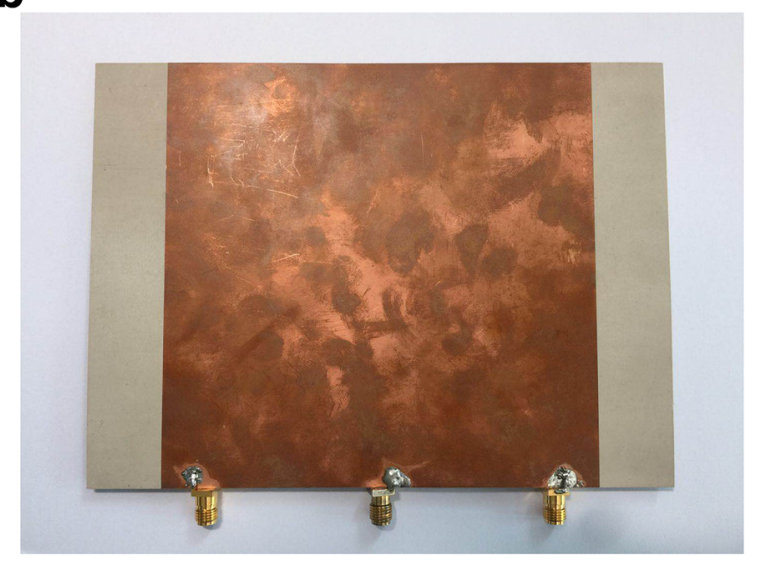

Fig. 6 Photographs of the radiating element. a TTop view. b Bottom view

2, and 3 correspond to the three antennas. It can be seen from Fig. 10 that the measured bandwidths of the two Yagi-Uda antennas are 9.49\% (5.22-5.74 GHz) and 9.21\% $(5.28-5.72 \mathrm{GHz})$, respectively, and are relatively wider than that of the patch antenna, which is only $0.36 \%(5.60-5.62 \mathrm{GHz})$. The bandwidth of the patch antenna can be improved by using aperture-coupled feeding [22], which will be done in our future work. The isolation between the radiating sub-elements is greater than $38 \mathrm{~dB}$. Theoretically, S11 and S33 should be close to each other, and S12 and S21 should be the same. The deviations in Fig. 10 may be caused by the fabrication tolerance and the measurement environment. In addition, because the values of S12 and S21 are very small and 


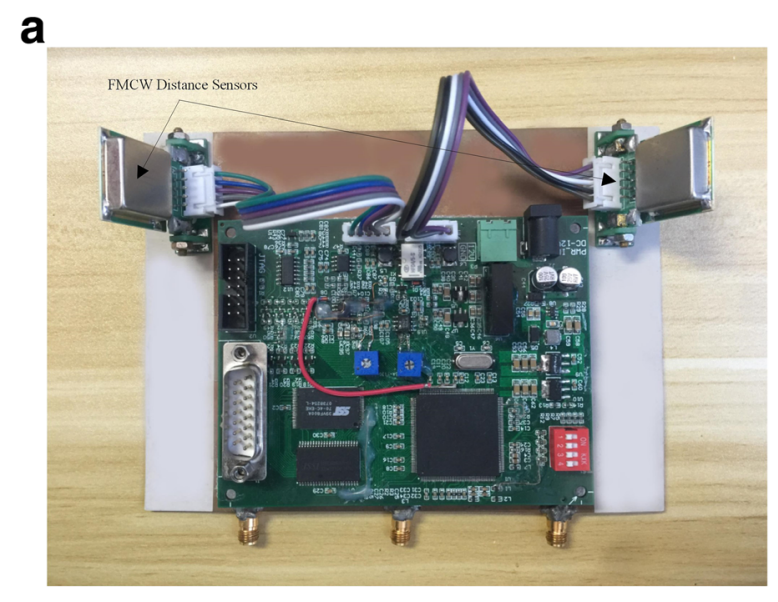

b

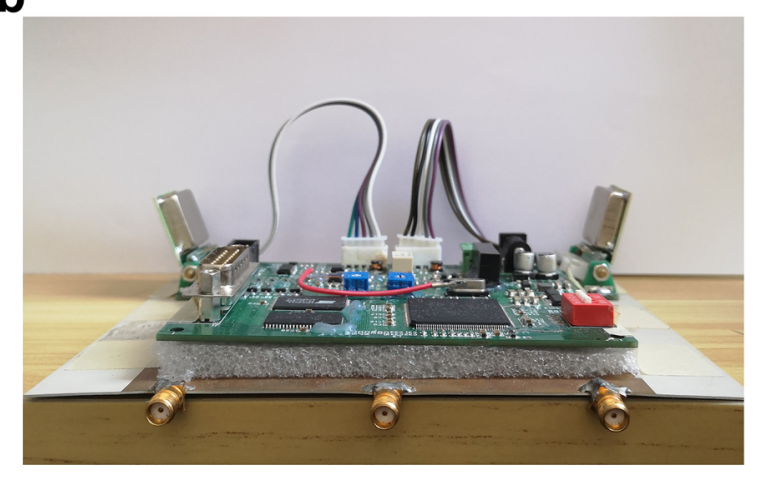

C

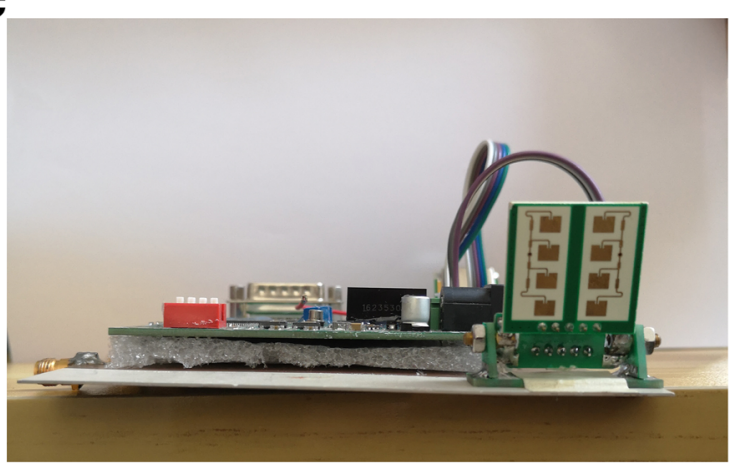

Fig. 7 Prototype of the smart antenna. a Top view. b Front view. c Side view

sensitive to the environment, if the antenna is moved slightly during measurement of S21 and S12, the two values will be different.

Figure 11 shows the measured radiation patterns of the sub-elements. The E-planes of sub-element 1 and sub-element 3 in Fig. 11a correspond to the $x-y$ plane shown in Fig. 5, whereas the E-plane of sub-element 2 corresponds to the $y-z$ plane, and the angles in the figures are counted from the $+z$ direction. Figure 11b shows the radiation patterns in the H-plane ( $x-z$ plane) of the three sub-elements. To facilitate observation, the radiation directions of the three elements are oriented to 90,180 , and $270^{\circ}$, corresponding to the $-x,-z$, and $+x$ directions, respectively. The measured gains of sub- 


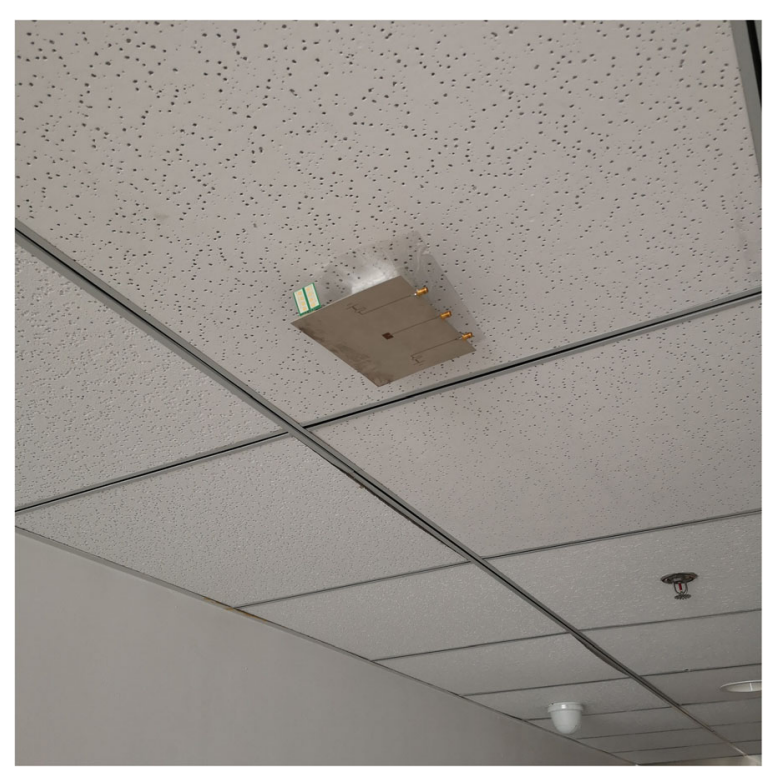

Fig. 8 Illustration of the mounting of the smart antenna

elements 1 to 3 at $5.61 \mathrm{GHz}$ are $5.34 \mathrm{dBm}, 2.24 \mathrm{dBm}$, and $4.94 \mathrm{dBm}$, respectively, and their normalized cross polarization levels are $-34.18 \mathrm{~dB},-40.91 \mathrm{~dB}$ and $-29.54 \mathrm{~dB}$.

\subsection{Performance of the smart antenna}

The radiation performance of the proposed antenna was measured in a real scenario of a long straight corridor in a large building. The corridor is $1.75 \mathrm{~m}$ in width and $2.4 \mathrm{~m}$ in height. Before measurement, the two sensors on the antenna were tested to obtain their effective sensing range. The relationship between the target distance and beat frequency signal is shown in Fig. 12, from which we can see that the sensing distance changes almost linearly with the beat frequency signal. Here, it is worth noting that the relationship between the target distance and beat frequency signal is considered basic knowledge and is deposited into the DSP before the measurement of the whole antenna system

The setup of the measurement system is shown in Fig. 13. The received level along the corridor was measured by an Agilent FieldFox RF Analyzer N9912A. The proposed antenna was suspended at a height of $1.9 \mathrm{~m}$ at the midpoint of the corridor in the

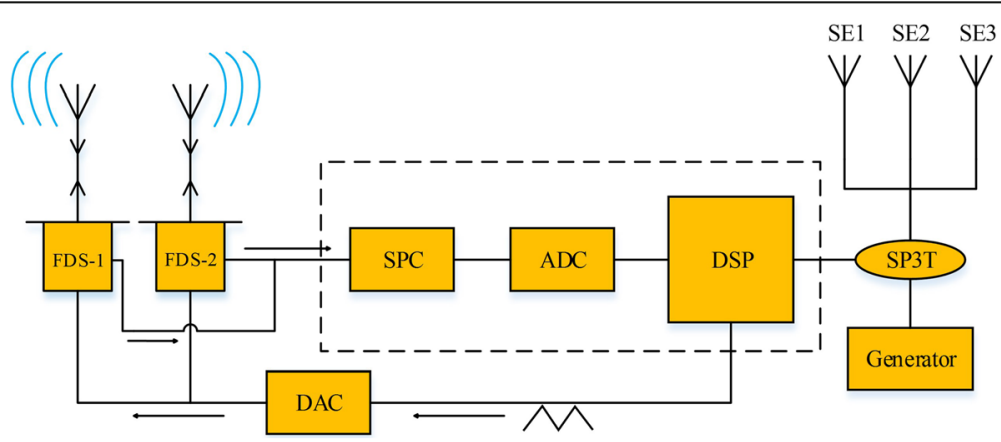

Fig. 9 Principle block diagram of the smart antenna. FDS and SPC denote the FMCW distance sensor and signal processing circuit, respectively 


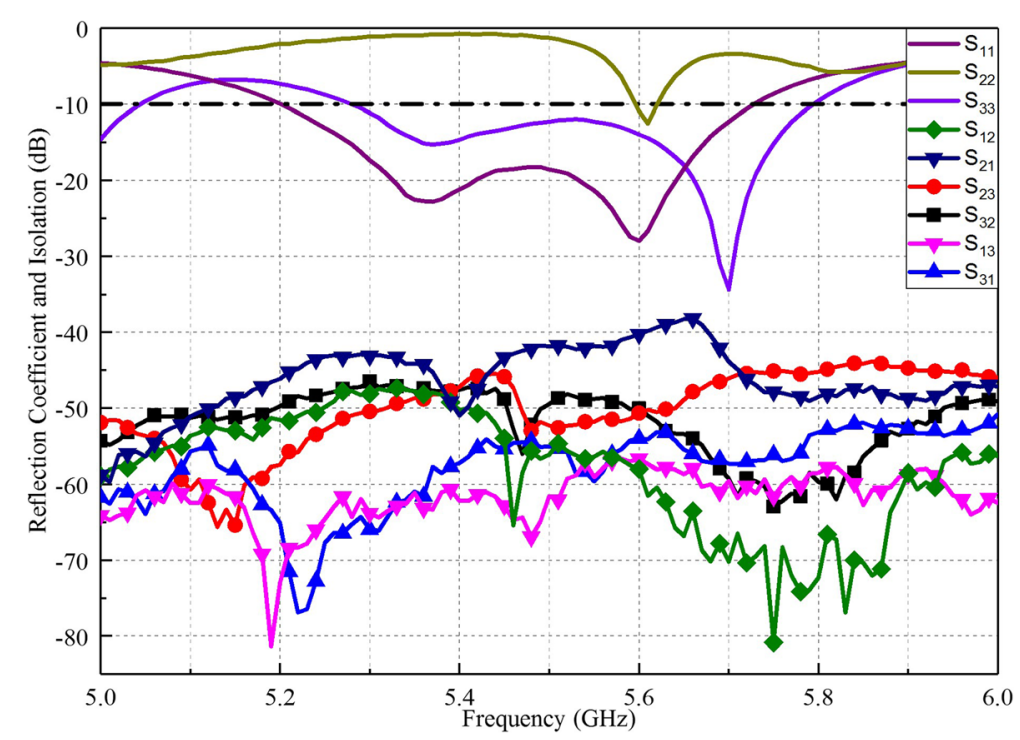

Fig. 10 Measured S-parameters of the three radiating subelements

horizontal direction. It was used as the transmitting antenna and was fed by an R\&S SMB100A signal generator with an operating frequency of $5.61 \mathrm{GHz}$. The receiving antenna was an omnidirectional antenna fixed on an antenna platform at a height of 1.35 $\mathrm{m}$. It was connected to the analyzer, and the analyzer was further connected to a computer to record the measurement data. During the measurement, the receiving terminal moved straight along the corridor at a constant speed, and the computer sampled the data in real time.

Figure 14 gives the distributions of the received power for the cases of exciting only one sub-element at a time during the test and for the case of exciting the appropriate sub-element in terms of the target position by means of automatic switching. As seen in Fig. 14a, when sub-element 1 is excited, the received power in zone 1 is higher than that in zone 3 and reaches its maximum at approximately $-1.3 \mathrm{~m}$. When sub-element 2 is excited, the peak of received power occurs at the zero position and attenuates gradually along both the $+x$ and $-x$ directions, as shown in Fig. 14b. Sub-element 3 has the same radiation characteristics as sub-element 1 but points in the opposite direction, so the received power curve is symmetric to that of sub-element 1, as shown in Fig. 14c. Here, we set the trigger distances to $+0.7 \mathrm{~m}$ and $-0.7 \mathrm{~m}$ to obtain a relatively smooth level reception. From the curve in Fig. 14d, we can see that when the proposed antenna is working in the mode of automatically switching between sub-elements in terms of the trigger distances, as expected, a relatively smother distribution of receiving power can be obtained.

We obtained different distributions of receiving power by changing the trigger distances, as illustrated in Fig. 15. For clarity and simplicity, we only show the power distributions on a half measurement path. As shown by the curve in Fig. 15a, for which the trigger distance was set to $-2 \mathrm{~m}$, the received power gradually increased when the receiving antenna moved from $-8 \mathrm{~m}$ towards the $+x$ direction. The increasing trend is denoted by a dashed line. In this case, a conspicuous drop occurs at approximately -2 $\mathrm{m}$, and the received power decreases below the dashed line before the receiving 

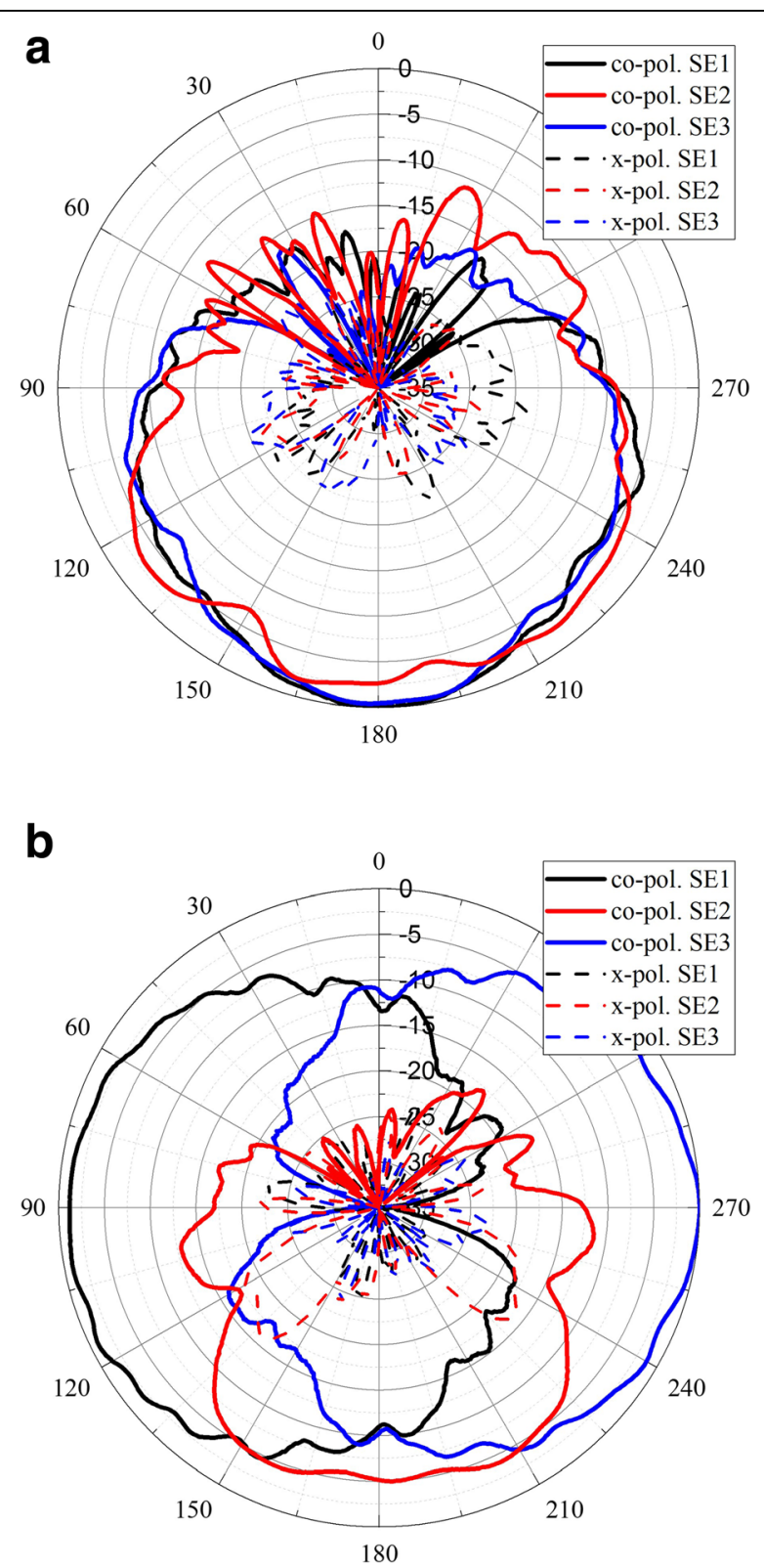

Fig. 11 Measured radiation patterns of the three radiating sub-elements of the smart antenna at $5.61 \mathrm{GHz}$ a E-plane. $\mathbf{b}$ H-plane

antenna reaches the switching position. The trends of the receiving power for other trigger distances are similar to that of $-2 \mathrm{~m}$. The only difference is the dropping position, which occurs at $-3 \mathrm{~m},-4 \mathrm{~m}$, and $-5 \mathrm{~m}$. Notably, for the trigger distance of -5 $\mathrm{m}$, the receiving power decreases more slowly from $-1.2 \mathrm{~m}$ to $-5 \mathrm{~m}$. The main reason is that the measurement environment is a corridor, which is a kind of confined space, and the waveguide effect can affect the propagation property, which is unlike that in free space.

To further validate the performance, the proposed antenna was applied to a wireless communication system to investigate the communication quality, as shown in Fig. 16. In the system, a pair of YunSDR Y320 baseband modules (comprising a generator, 


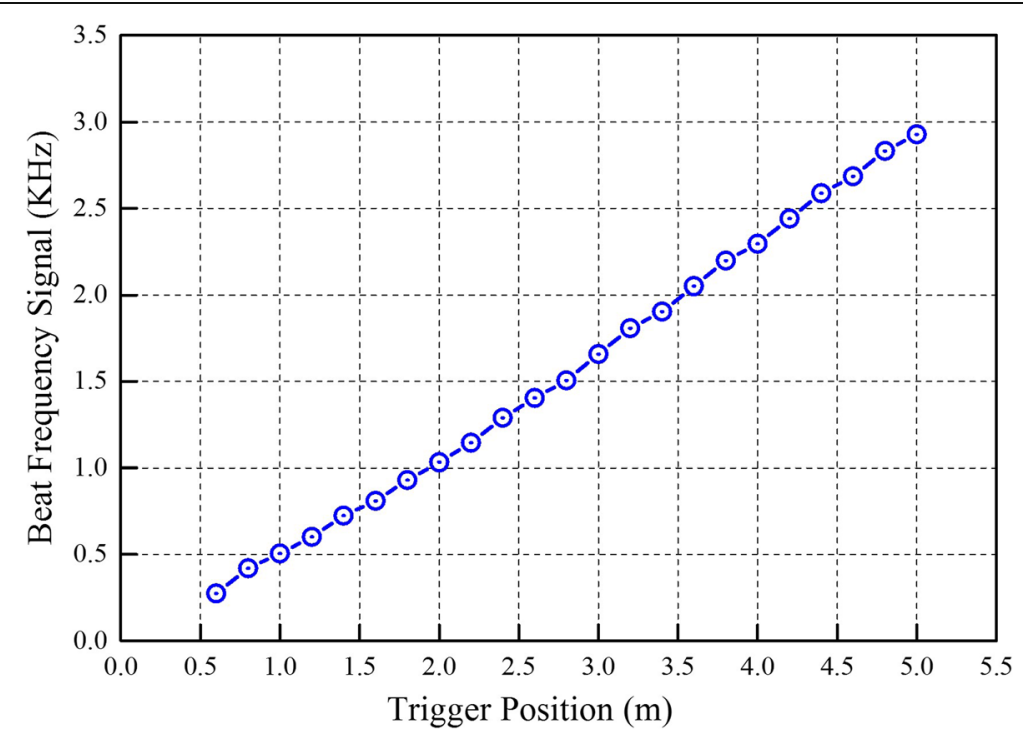

Fig. 12 Measured relationship between trigger position and beat frequency signal

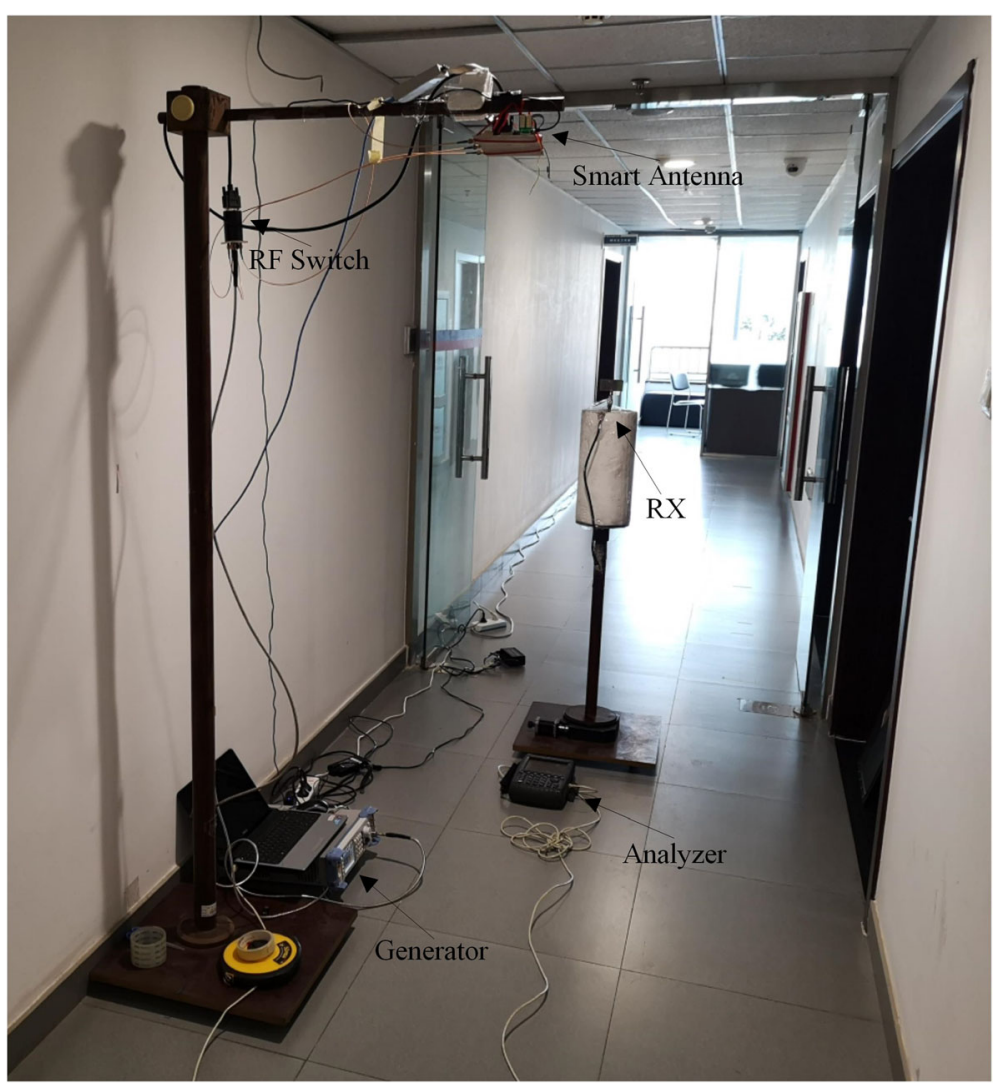

Fig. 13 Setup of receiving level measurement of the smart antenna 


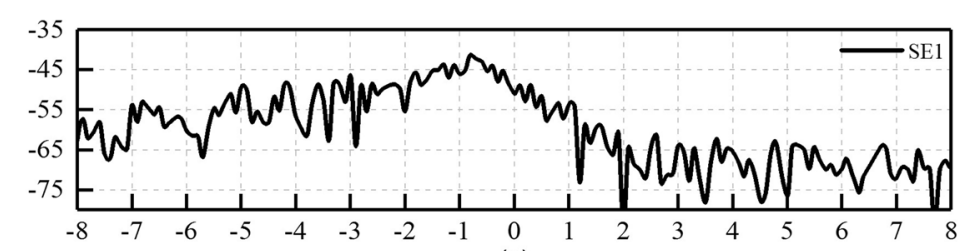

(a)

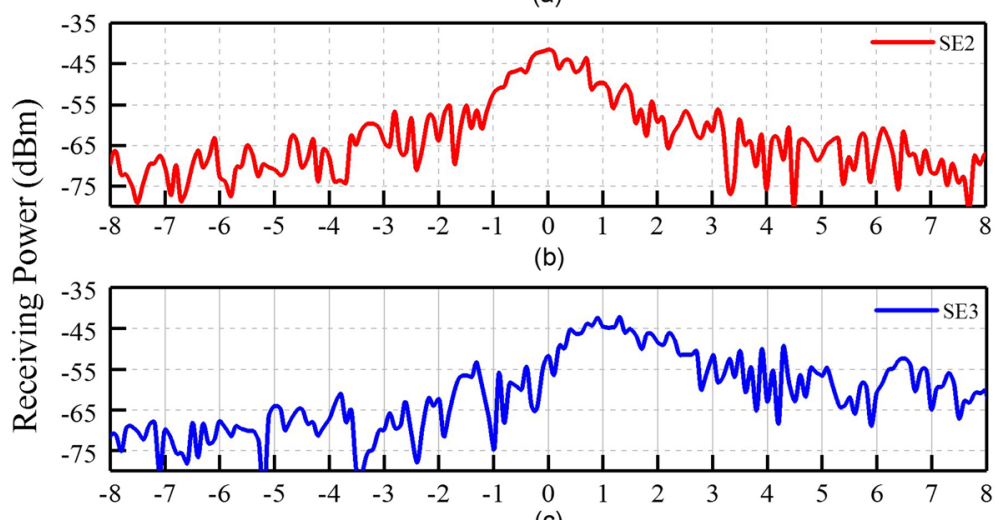

(c)

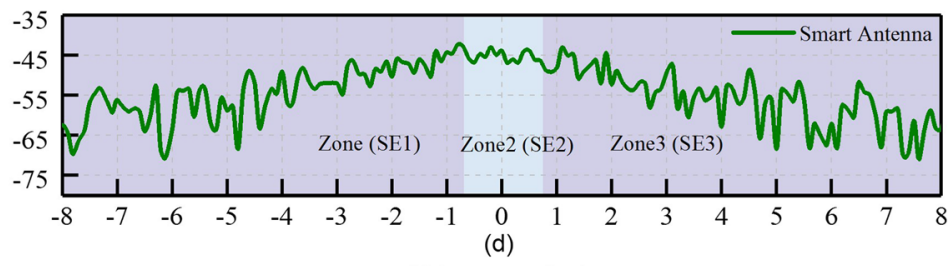

Distance (m)

Fig. 14 Distributions of the received power for the transmitting antenna operating in different modes, (a), (b) and (c) are the curves measured along the whole path when only one subelement is excited at a time (without switching), (d) is the curve measured when the antenna is operated in the mode of automatic switching in terms of trigger distance

encoder and decoder) and quadrature phase-shift keying (QPSK) modulation mode were used to perform the measurement. In the transmitting terminal, a Y320 was connected to a computer to receive orders and data. The processed data frames with a bandwidth of 20 Mbps were modulated on a carrier frequency at $5.61 \mathrm{GHz}$ and were continuously sent to the proposed antenna via an RF switch. After starting, the data frames propagating in the wireless channel were received by the receiving antenna. Finally, the data sent by the first computer were obtained by another computer.

In this part of the measurement, the error vector magnitude (EVM) [25], an index to evaluate the performance of the whole system, was tested, with a sampling interval of $0.2 \mathrm{~m}$ along the measurement path. The EVM is expressed by

$$
\mathrm{EVM}=\sqrt{\frac{P_{\text {error }}}{P_{\text {reference }}}} \times 100 \%
$$

where $P_{\text {error }}$ is the average power of the error vector and $P_{\text {reference }}$ is the average power of the reference signal.

The results are shown in Fig. 17. The trigger positions were set at $-1 \mathrm{~m}$ and $+1 \mathrm{~m}$, which means that the range of zone 1 is from $-8 \mathrm{~m}$ to $-1 \mathrm{~m}$, and the ranges of zones 2 and 3 are from $-1 \mathrm{~m}$ to $1 \mathrm{~m}$, and from $1 \mathrm{~m}$ to $8 \mathrm{~m}$, respectively. The performance of the whole system was tested for individual sub-elements without switching and for the 


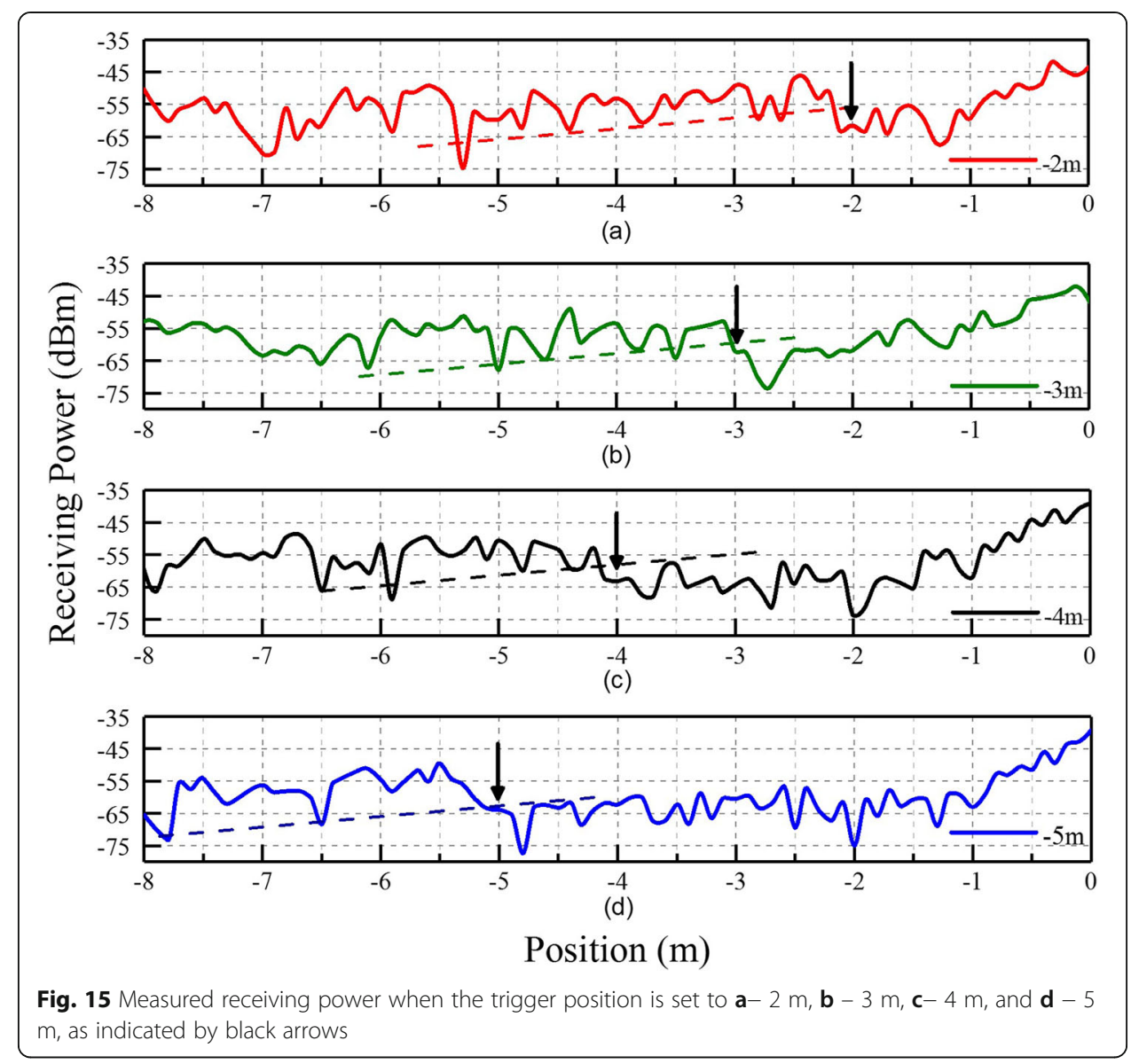

case of automatic switching between sub-elements in terms of trigger distance. The results are shown in Fig. 17a-d. When the three sub-elements are excited individually, as the three curves in Fig. 17a-c show, small-scale fluctuation can be observed in the range of $60 \%$, which is caused mainly by intersymbol interference on account of the multipath effect in the tested corridor. On the other hand, considering zone 1, when only subelement 1 is excited, the maximum value of EVM is approximately $60 \%$ at $-7.1 \mathrm{~m}$. When only sub-element 2 or 3 is excited, as shown by the curves in Fig. 17b, c, respectively, most

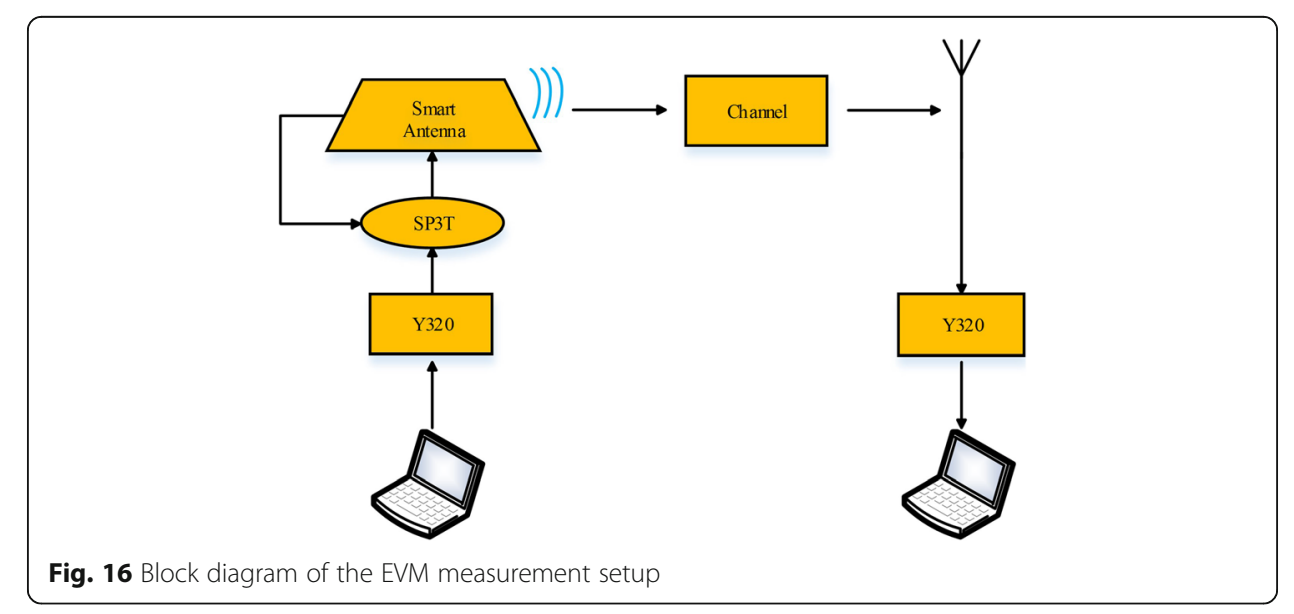


a

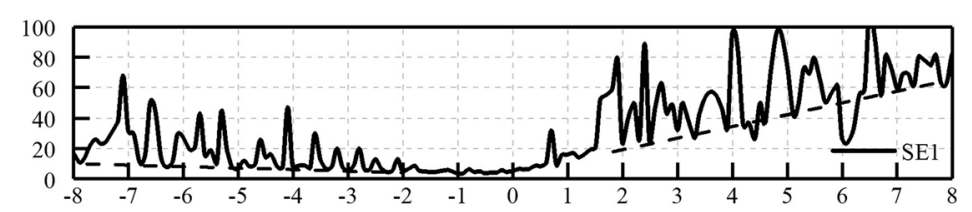

b

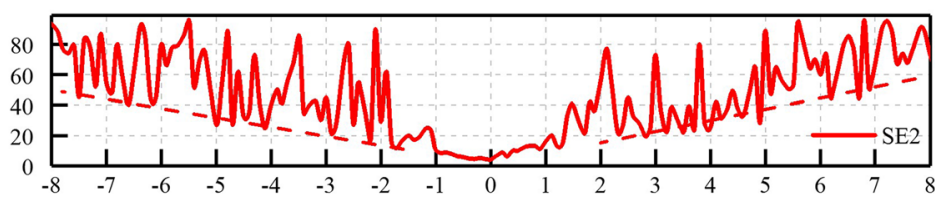

C

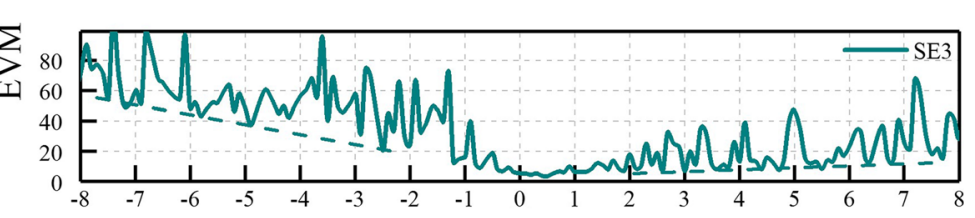

d

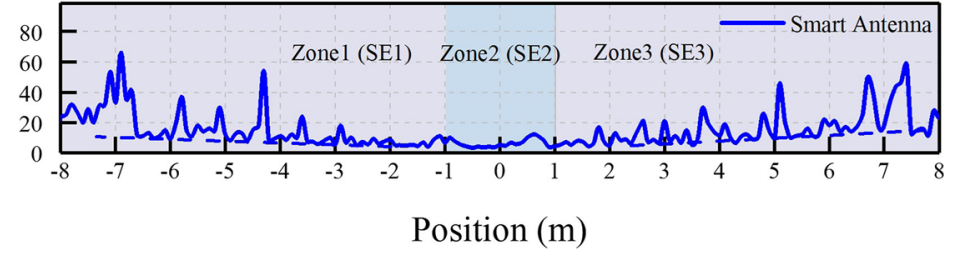

e

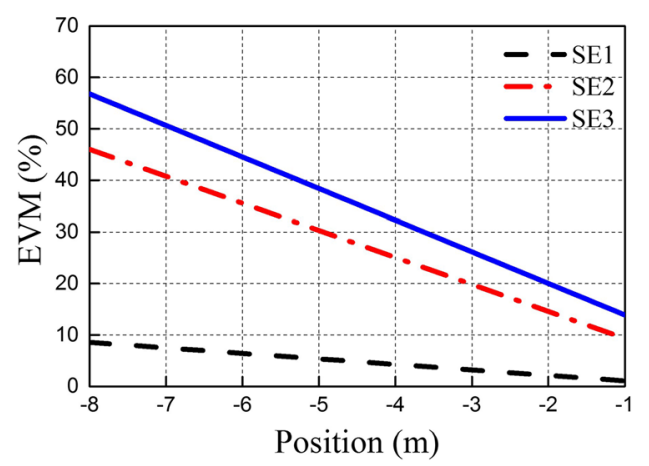

f

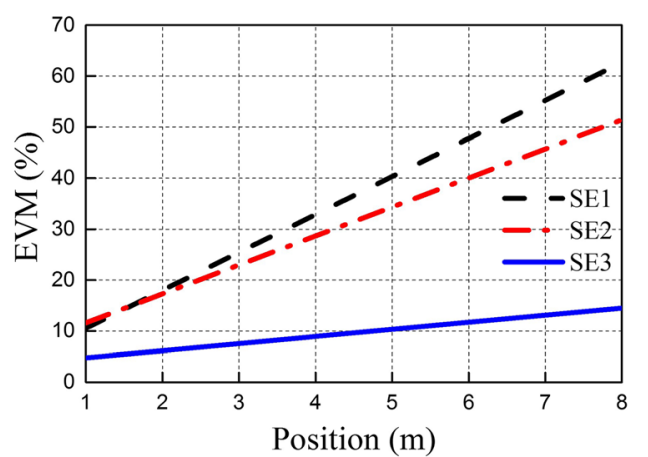

Fig. 17 (See legend on next page.) 
(See figure on previous page.)

Fig. 17 Distributions of EVM for a transmitting antenna operating in different modes. The three curves in a, $\mathbf{b}$, and $\mathbf{c}$ were measured along the whole path when only one element was excited at a time (without switching). The curve in $\mathbf{d}$ was measured when the antenna was operated in the mode of automatic switching in terms of trigger distance. e Lower envelope of EVM of the curves in $\mathbf{a}, \mathbf{b}$, and $\mathbf{c}$ in zone 1 . $\mathbf{f}$ Lower envelope of EVM of the three curves in $\mathbf{a}, \mathbf{b}$, and $\mathbf{c}$ in zone 3

of the EVM is located in the upper half of the figures, namely, above $50 \%$, even exceeding $100 \%$ at $-7.4 \mathrm{~m}$ when only sub-element 3 is excited. In zone 2, the curves in Fig. 17a, c show that the EVM is not stable near the two trigger boundaries. However, when subelement 2 is active, the EVM exhibits optimal performance in zone 2. The structure of sub-element 3 is identical to that of sub-element 1 , so it performs best in zone 3 . Furthermore, in zones 1 and 3, each curve in Fig. 17a-c has a lower envelope, which can be used to adjust the performance of the radiating sub-elements more explicitly. In Fig. 17e, the envelopes of the radiating sub-elements in zone 1 are fitted out. The EVM derived from the signal received by sub-element 1 is the lowest, while the EVMs for subelements 2 and 3 are higher. However, in zone 3 , sub-element 3 is the best choice of the three subelements. Figure 17e, $\mathrm{f}$ are not symmetric because the impacts of the testing environment are asymmetric, as shown in Fig. 13. In addition, the time variation of the wireless channel is also an influencing factor. The curve in Fig. 17d shows the case of trigger positions at 1 and $1 \mathrm{~m}$, from which it can be seen that the lower envelope of EVM remains relatively lower in zones 1 and 3 compared to those in the three curves in Fig. 17a-c, and the EVM in zone 2 is more stable and lower, which means that the proposed antenna guarantees the communication quality of the wireless communication system. In this paper, we show only the results measured in a confined space, but our design can also be extended to mobile communication in open spaces such as highways or railways.

\section{Conclusion}

This paper presents a new kind of smart antenna with the capability of automatic beam switching and low complexity. The antenna consists of sensing, signal processing, and radiating elements. In the sensing element, two $24 \mathrm{GHz}$ radar sensors based on FMCW are used to detect the distances of targets. A signal processing circuit is designed to extract the beat frequency signal from the output of the sensors. In the radiating element, two Yagi-Uda antennas for endfire radiation and one patch antenna for broadside radiation are designed on a Rogers 6010 substrate with the same polarization and overlapping working frequency band. To verify the performance of the proposed antenna, measurements in a long corridor were performed. The results show that the communication quality can be improved by the smart antenna, which could be used for vehicles to facilitate future mobile communication.

\footnotetext{
Abbreviations

EVM: Error vector magnitude; FMCW: Frequency-modulated continuous wave; VCO: Voltage-controlled oscillator; ADC: Analog-to-digital conversion; PCB: Printed circuit board; QPSK: Quadrature phase-shift keying
}

\section{Acknowledgements}

The datasets analyzed during the current study are not publicly available since they involve a confidentiality agreement but are available from the corresponding author upon reasonable request.

Authors' contributions

JW conceived the idea. YM completed the smart antenna and wrote this paper. $Y L, M C, Z L$, and $Z Z$ contributed to the review of the manuscript. All authors read and approved the final manuscript. 


\section{Funding}

This work was supported in part by the National Natural Science Foundation of China under Grants 61871025 and 61331002.

\section{Availability of data and materials}

Not applicable

\section{Competing interests}

The authors declare that they have no competing interests.

Received: 29 November 2019 Accepted: 6 September 2020

Published online: 15 September 2020

\section{References}

1. P. Howells, Explorations in fixed and adaptive resolution at GE and SURC. IEEE Trans. Antennas Propag. 24(5), 575-584 (1976). https://doi.org/10.1109/TAP.1976.1141401

2. T. Huang, P. Pan, H. Hsu, Adaptive beam steering smart antenna system for ultra-high-frequency radio frequency identification applications, 2012 (International Symposium on Computer, Consumer and Control, Taichung, 2012), pp. 713-716. https://doi.org/10.1109/IS3C.2012.185

3. H. Liu, S. Gao, T.H. Loh, Frequency agile small smart antenna (Proceedings of the Fourth European Conference on Antennas and Propagation, Barcelona, 2010), pp. 1-4

4. C. Gu et al., Compact smart antenna with electronic beam-switching and reconfigurable polarizations. IEEE Trans. Antennas Propag. 63(12), 5325-5333 (Dec. 2015). https://doi.org/10.1109/TAP.2015.2490239

5. Ming-lu Lai, Tjung-Yu Wu, Jung-Chin Hsieh, Chun-Hsiung Wang and Shyh-Kang Jeng, A miniature, planar, and switched beam smart antenna employing a four- element slot antenna array for Digital Home applications, 2007 IEEE Antennas and Propagation Society International Symposium, Honolulu, Hl, 2007, pp. 3376-3379. doi: https://doi.org/10.1109/APS. 2007.4396261

6. A.B. Guntupalli, K. Wu, $60 \mathrm{GHz}$ circularly-polarized smart antenna system for high throughput two-dimensional scan cognitive radio (2013 IEEE MTT-S International Microwave Symposium Digest (MTT), Seattle, 2013), pp. 1-3. https://doi. org/10.1109/MWSYM.2013.6697662

7. R.M.S. De Oliveira, V. Dmitriev, Graphene Antenna, no. (2018)

8. D. Salama, M.N. Abdallah, T.K. Sarkar, M. Salazar-Palma, Smart non-uniform antenna arrays deployed above an imperfect ground lane at multiple frequencies, vol 2017-Janua (2017 IEEE-APS Top. Conf. Antennas Propag. Wirel. Commun. APWC 2017, 2017), pp. 292-295

9. S. Kalra, R. Datta, B. S. Munjal, and B. Bhattacharya, Smart reconfigurable parabolic space antenna for variable electromagnetic patterns, IOP Conf Ser Mater Sci Eng, vol. 311, no. 1, pp. 0-8, 2018.

10. A. Singh, J. Kyllonen, S. Caduc, J. Shamblin, M. Garg, A. Horie, Compact smart antenna system for improving probability of detection (2017 IEEE International Symposium on Antennas and Propagation \& USNC/URSI National Radio Science Meeting, San Diego, 2017), pp. 1383-1384

11. X. Wang, E. Aboutanios, Reconfigurable adaptive linear array signal processing in GNSS applications (2013 IEEE International Conference on Acoustics, Speech and Signal Processing, Vancouver, 2013), pp. 4154-4158. https://doi.org/ 10.1109/ICASSP.2013.6638441

12. X. Wang, E. Aboutanios, M. Trinkle, M.G. Amin, Reconfigurable adaptive array beamforming by antenna selection. IEEE Trans. Signal Process. 62(9), 2385-2396 (2014)

13. A.H. El Zooghby, C.G. Christodoulou, M. Georgiopoulos, A neural network-based smart antenna for multiple source tracking. IEEE Trans. Antennas Propag. 48(5), 768-776 (2000). https://doi.org/10.1109/8.855496

14. Z. Li, E. Ahmed, A.M. Eltawil, B.A. Cetiner, A beam-steering reconfigurable antenna for WLAN applications. IEEE Trans. Antennas Propag. 63(1), 24-32 (2015). https://doi.org/10.1109/TAP.2014.2367500

15. K. Tateishi et al., Indoor experiment on $5 \mathrm{G}$ radio access using beam tracking at $15 \mathrm{GHz}$ band (2016 IEEE 27th Annual International Symposium on Personal, Indoor, and Mobile Radio Communications (PIMRC), Valencia, 2016), pp. 1-6. https://doi.org/10.1109/PIMRC.2016.7794570

16. E. Guariglia, Entropy and Fractal Antennas. Entropy 18 (2016). https://doi.org/10.3390/e18030084

17. E. Guariglia, Harmonic Sierpinski Gasket and Applications. Entropy 20, 714 (2018). https://doi.org/10.3390/e20090714

18. K.-L. Chan, S.R. Judah, A beam scanning frequency modulated continuous wave radar. IEEE Trans. Instrum. Meas. 47(5), 1223-1227 (1998). https://doi.org/10.1109/19.746587

19. P.V. Brennan, Y. Huang, M. Ash, K. Chetty, Determination of Sweep Linearity Requirements in FMCW Radar Systems Based on Simple Voltage-Controlled Oscillator Sources. IEEE Trans. Aerosp. Electron. Syst. 47(3), 1594-1604 (2011). https://doi.org/10.1109/TAES.2011.5937252

20. E. Guariglia, Riemann zeta fractional derivative-functional equation and link with primes. Adv Differ Equ 261 (2019)

21. W.R. Deal, N. Kaneda, J. Sor, Y. Qian, T. Itoh, A new quasi-Yagi antenna for planar active antenna arrays. IEEE Transac. Microwave Theory Tech. 48(6), 910-918 (2000). https://doi.org/10.1109/22.846717

22. C.A. Balanis, Antenna theory: analysis and design (1982)

23. M. Frongillo, G. Gennarelli, G. Riccio, Diffraction by a structure composed of metallic and dielectric $90^{\circ}$ blocks. IEEE Antennas Wireless Propagation Letters 17(5), 881-885 (2018). https://doi.org/10.1109/LAWP.2018.2820738

24. M. Frongillo, G. Gennarelli, G. Riccio, TD-UAPO diffracted field evaluation for penetrable wedges with acute apex angle. J Opt. Soc. Am. Optics Image Sci. Vision (2015)

25. GSM 05.05 V8.2.0-Digital cellular telecommunications system (phase 2+); radio transmission and reception. ETSI, 1999

\section{Publisher's Note}

Springer Nature remains neutral with regard to jurisdictional claims in published maps and institutional affiliations. 